\title{
BALDUS, CHRISTIAN; FINKENAUER; THOMAS; RÜFNER, THOMAS (ED.). JURISTENAUSBILDUNG IN EUROPA ZWISCHEN TRADITION UND REFORM. (FORMAÇÃO DE JURISTAS EM EUROPA ENTRE TRADIÇÃO E REFORMA). MOHR SIEBECK, 2008. 388 P., ISBN 978-3-16-149578-6
}

JURISTENAUSBILDUNG IN EUROPA - ZWISCHEN TRADITION UND REFORM. (FORMATION OF JURISTS IN EUROPE - BETWEEN TRADITION AND REFORM"). AUTHORS: CHRISTIAN BALDUS / THOMAS FINKENAUER. MORH SIEBECK, 2008, 388S. ISBN: 978-3-16-149578-6

Thomas Richter*

O livro é retrato de uma conferência internacional de professores de Direito, que teve lugar em Trier, Alemanha, de 23 a 25 de novembro de 2007, sobre a formação de juristas na Europa na época do chamado Processo de Bologna, que visa à harmonização da formação universitária.

O Processo de Bologna foi iniciado em 1999 com uma primeira conferência dos secretários de Educação dos países europeus, na cidade de Bologna, Itália, tendo por objetivo o desenvolvimento de uma "área européia de educação superior" até o ano 2010. Esse objetivo deve ser atingido por meio da instituição de um sistema de estudos de três ciclos (bacharelado, mestrado e doutorado), melhor reconhecimento de graus e qualificações acadêmicos, fomento à mobilidade, à transparência e à implementação de medidas de garantia de qualidade. A conferência dos secretários de Educação se reúne bianualmente. A última reunião foi em Londres, em 2007. Participam quase todos os países europeus, entre eles todos os Estados-Membros da União Européia. O Processo de Bologna não faz parte do Direito comunitário e não vincula legalmente os Estados participantes.

É neste contexto que os professores de Direito analisaram a formação de juristas, separando, cronologicamente, (1) a história da formação de juristas, (2) o status quo da formação de juristas em vários países europeus, nos Estados Unidos e nos países da América Latina, e (3) conclusões para Alemanha. O livro documenta tanto as palestras, em forma de artigo científico, quanto os debates.

$\mathrm{Na}$ primeira parte, a parte histórica, seis palestrantes informam sobre a formação jurídica e a função dos juristas na República romana até a Prússia e Alemanha do século 19. Aprendemos com Emanuele Stolfi que é no início da República romana que a jurisprudência foi desenvolvida pelos sacerdotes. Devidamente consultados pelos patres familias, eles davam os responsa, opiniões jurídicas, voltadas ao caso concreto. É necessário destacar que essas opiniões eram proferidas oralmente, de forma secreta e

\footnotetext{
* Professor visitante pelo Serviço Alemão de Intercâmbio Acadêmico na Faculdade de Direito da Universidade de São Paulo. Doutor em Direito Internacional pela Universidade de Konstanz (Constança), Alemanha.
} 
sem fundamentação. A formação dos futuros pontifices limitava-se à presença na hora dos responsa, dados no ambiente familiar. Nos últimos anos da República, porém, a jurisprudência tornou-se pública, complementando a responsum por um debate jurídico posterior. Assim desenvolveu-se o ius controversum, que permite opiniões diversas. Detlef Liebs informa sobre a última época do Império romano, que trouxe, na parte oriental, uma formação jurídica em entidades públicas de ensino e com um plano de estudos de cinco anos, que começava com cadeiras básicas como Filosofia do Direito e abrangia Direito civil, penal e público. O diploma de estudos jurídicos tornou-se, cada vez mais, um requisito para se adquirir cargos na justiça e no serviço público superior. A formação jurídica na Idade média, explicada por Hans Wieling, passa por um declínio, para renascer, no século XI, pelas técnicas lógicas da escolástica e na fundação das primeiras universidades. As próximas três palestras informam sobre a história mais recente da formação jurídica na França (Yves Mausen), na Inglaterra (Michael Lobban) e na Prússia/Alemanha (Peter Krause), esta última demonstrando o desenvolvimento do "jurista uniforme" alemão, ou seja, uma formação jurídica igual para todos os juristas, qualificando-as ao cargo de juiz e, ao mesmo tempo, àqueles de promotor de justiça, de advogado e de funcionário público superior. Em debate posterior às palestras, os participantes do evento destacaram que a formação jurídica, apesar da necessidade de transferir conhecimentos padronizados, deve educar os jovens juristas a trabalharem de maneira científica e independente.

A segunda parte consiste em onze relatórios sobre a formação jurídica na Áustria, na Hungria, na Polônia, na Grã-Bretanha, na Finlândia, nos Países-Baixos, na França, na Itália, na Espanha, nos Estados Unidos e nos países da América Latina. O estudo jurídico nos países europeus divide-se em uma fase de estudos universitários e uma fase posterior de estágio probatório, ambas necessárias para obter o direito de praticar, de maneira autônoma, uma profissão jurídica. Os países europeus estão passando por uma fase de "bolognização" dos sistemas universitários, enfrentando, porém, bastante resistência na área jurídica. Na Áustria, por exemplo, conforme informa Verena Tiziana Halbwachs, a lei sobre a alteração do Direito das Profissões de 2008 (Berufsrechtsänderungsgesetz 2008) estabelece um sistema de créditos compatíveis com o sistema europeu, mas estipula um curso jurídico único de quatro anos, derrogando, assim, para a área jurídica, o processo de Bologna já internalizado pela lei sobre as universidades de 2002. Na Hungria (András Földi) o sistema de Bologna foi instituído por lei vigente, a partir do ano letivo 2006/2007, mas um decreto governamental garante o modelo tradicional da formação jurídica. A Itália (Paulo Flavio Mondini) reformou, já no inicio da década, a formação jurídica, estabelecendo um primeiro ciclo (bachelor) de três anos e um segundo ciclo (master) de dois anos - porém, o insucesso do bachelor levou a uma contra-reforma, que previu um curso jurídico regular de cinco anos, com a possibilidade do estudante sair da faculdade com o título de bachelor após três anos. Esta solução coloca-se, aliás, na tradição da idade 

reforma). Mohr Siebeck, 2008. 388 p., ISBN 978-3-16-149578-6

média de atribuir o título de baccalaureus a todo estudante avançado, mas não como grau acadêmico. Na Alemanha, a Conferência dos Secretários da Justiça dos Estados, de 17 de novembro de 2005, decidiu não aplicar o sistema de Bologna na formação dos juristas.

Muitos países europeus e a maioria dos palestrantes vêem mais argumentos em desfavor do que a favor da implementação do Processo de Bologna. Admitem, de um lado, que um sistema europeu de créditos deveria facilitar a mobilidade acadêmica dos estudantes, mas destacam, do outro lado, que um plano denso de estudos de seis semestres até a concessão do título de bachelor raramente deixa espaço para estudos no estrangeiro - argumento que seria validado pela queda de intercâmbio nos cursos já baseados no sistema de Bologna. A maior preocupação é, porém, com uma eventual diminuição da alta qualidade da formação jurídica, caracterizada pelo raciocínio autônomo e científico, e estabelecida ao longo da história, conforme demonstrado na primeira parte do livro.

Para os leitores desta Revista, cabe apontar para o relatório de Augusto Jaeger Junior sobre a formação jurídica na América latina, especificamente sobre o projeto "Tuning América Latina", um projeto entre a União Européia e América Latina que estuda as seguintes perguntas: "Existem na América Latina experiências comparáveis àquelas do Processo de Bologna? Seriam elas frutíferas para a ciência jurídica? Quais as causas da falta de experiências comparáveis e por que as tentativas latino-americanas ficaram sem êxito?" O projeto recolheu dados empíricos e opiniões de especialistas, enfatizando a comparação com a situação européia e o futuro da formação jurídica, e suas conclusões podem ser assim resumidas:" o curso de Direito é, em média, de cinco anos. Há muitas faculdades privadas, nas quais a qualidade de ensino costuma ser inferior àquela das públicas. Em muitas entidades, os processos de estudo têm como base uma metodologia de assimilação não-crítica de afirmações teóricas ou de memorização de normas jurídicas. O Brasil, porém, estabeleceu, com o exame da Ordem dos Advogados do Brasil, uma porta de entrada à profissão de advogado. Tal forma de garantia de qualidade fora da Faculdade é singular na América Latina. A mobilidade dos estudantes ainda não está muito desenvolvida. Quanto à mobilidade internacional, o foco está mais voltado aos Estados Unidos e à Europa. Os Estados-Membros do Mercosul estabeleceram requisitos mínimos ao plano de estudo na formação jurídica. O mais rígido é o brasileiro, com uma carga horária de 3.600 horas, em cinco anos de estudo. O Protocolo de Integração Educativa para Prosseguimento de Estudos de Pós-Graduação nas Universidades dos Estados-Partes do Mercosul, de 17 de dezembro de 1996 (Mercosur/CMC/Dec. n. 8/96), em vigor desde 26 de agosto de 1999, não parece ter desenvolvido uma importância significante na área da formação jurídica.

$\mathrm{Na}$ terceira parte do livro, os participantes expõem suas conclusões e as relacionam com o debate sobre o futuro da formação jurídica na Alemanha. Prevalecem as vozes céticas em relação à necessidade e conveniência da aplicação do sistema de 
Bologna. As provas por módulo não poderiam, por exemplo, demonstrar aptidão para o estágio probatório e o exercício de uma profissão jurídica. $\mathrm{O}$ reconhecimento de advogados alemães como iguais aos juizes não deveria ser consagrado por um modelo que produziria "parajuristas" (Müller-Graff), inaptos para resolver com serenidade os conflitos da sociedade.

São Paulo, dezembro de 2008. 